\title{
Potentials of Mouthwashes in Disinfecting Cariogenic Bacteria and Biofilms Leading to Inhibition of Caries
}

\author{
Takehiro Oyanagi ${ }^{\mathrm{a}}$, Junji Tagami ${ }^{\mathrm{a}, \mathrm{b}}$ and Khairul Matin ${ }^{\mathrm{a}, \mathrm{c}_{*}}$
}

${ }^{a}$ Cariology and Operative Dentistry, Department of Restorative Sciences, Graduate School of Medical and Dental Sciences, Tokyo Medical and Dental University, ${ }^{b}$ Global Center of Excellence Program; International Research Center for Molecular Science in Tooth and Bone Diseases, Tokyo Medical and Dental University, ${ }^{c}$ PerfectPerio Co. Ltd., Tochigi, Japan

\begin{abstract}
Objectives: The aim of this study was to compare the effects of certain commercially available mouthwashes on cariogenic bacteria and biofilms, following the acquisition of inhibition potentials of caries. Materials and Methods: Mouthwashes containing I) chlorhexidine gluconate (CHG; $0.0005 \% \mathrm{w} / \mathrm{v})$, II) benzethonium chloride (BTC; 0.01\% w/v), III) an essential oil (Listerine), and IV) povidone-iodine (PVP-I; 0.035\% w/v) were tested on planktonic cariogenic bacteria, biofilms, and an ex vivo caries model. Bacterial aliquots were inoculated with each solution separately and vortexed for 10 seconds at room temperature. Bacterial viability was subsequently investigated by fluorescence microscopy (FM) after staining with a BacLight viability kit and the number of colony-forming units (CFUs) was counted. Similarly, mouthwash solutions were applied to artificial cariogenic biofilms, and bacterial viability of the biofilms was investigated as stated above. Inhibition potentials of two selected mouthwashes of carious lesions were investigated using biofilm-induced caries and a secondary caries model. In all steps, a phosphate-buffered saline (PBS) solution was included as a control. Results: Planktonic cariogenic bacteria and bacteria embedded in biofilms were killed in remarkably large numbers with Listerine and PVP-I treatment compared to PBS and other gargles. CFU counts also showed significant reduction after treatment with Listerine and PVP-I compared to other solutions $(\mathrm{P}<0.05)$. Listerine also displayed significant $(\mathrm{P}<0.05)$ inhibition effects in preventing the progression of demineralization. Conclusion: Bactericidal potencies of the mouthwashes varied significantly, suggesting that mouthwashes like Listerine can be useful for the prevention of caries and secondary caries.
\end{abstract}

Keywords: Cariogenic bacteria, cariogenic biofilms, inhibition of caries and secondary, mouthwashes, prevention of caries and secondary caries.

\section{INTRODUCTION}

The oral cavity is one of the most complex parts of the human body that consists of teeth, periodontal tissue, tongue and mucosa as well as secretory organelles and harbors a heterogeneous microbial community $[1,2]$. The oral cavity remains highly prone to infectious diseases $[2,3]$. Hundreds of bacterial species are involved in dental caries [4]; e.g., Streptococci species as well as lactobacillus species [5, 6]. Mutans streptococci generally include Streptococcus mutans and Streptococcus sobrinus in the biofilms and produce acids as a by-product of metabolism of fermentable carbohydrates $[7,8]$.

In recent years, there has been more concern about caries prevention and a call for preventive home care articles [9, 10]. Other than tooth brushing there are many mouthwashes available which appear to be more popular than tooth brushing in terms of convenience [10].

\footnotetext{
*Address correspondence to this author at the Cariology and Operative Dentistry, Department of Restorative Sciences, Graduate School of Medical and Dental Sciences, Tokyo Medical and Dental University 1-5-45 Yushima, Bunkyo-ku, Tokyo, Japan; 113-8549; Tel: +81-3-5803-4623/4624, Fax: +81-3-5803-0195, E-mail: matin.ope@tmd.ac.jp
}

Antiseptic mouth rinse solutions are used in many clinical situations for different therapeutic and prophylactic purposes $[11,12]$. Many of those are recommended for homecare practice [11]. It is difficult to decide which commercial product is suitable for a particular purpose because of the variations of the antimicrobial efficacy, cytotoxicity and kinetics of the solutions [13]. The main indications are either the improvement of dental health (plaque and gingivitis elimination in particular) or the prevention of infections caused by bacteria of the oral cavity in specific situations such as tooth extraction, intraoral surgical procedures or immune-suppression during cancer therapy or transplantation [14]. Occasionally, antimicrobial mouthwashes have been prescribed for controlling the levels of cariogenic bacteria and their plaque biofilms [15].

The objectives of this study were to compare the bactericidal effects of some commercially available mouthwashes on cariogenic bacteria and their effects on cariogenic biofilms. In addition, it was examined whether the application of mouthwash can inhibit the progression of demineralization by using an artificial caries and secondary caries model. 
Table 1. Solutions Used in this Study

\begin{tabular}{|c|c|c|c|}
\hline Solution & Ingredients & Manufacturer & pH \\
\hline $\begin{array}{c}\text { Neostelin Green }^{\circledR} \\
\text { benzethonium chloride (BTC) (x20) }\end{array}$ & $0.2 \%$ benzethonium chloride & Nippon Shika Yakuhin Co., Ltd, Yamaguchi, Japan & 7.6 \\
\hline $\begin{array}{l}\text { Listerine }^{\circledR} \\
\text { (Original) }\end{array}$ & $\begin{array}{c}0.09 \% 1.8 \text {-cineol } \\
0.06 \% \text { thymol } \\
0.05 \% \text { Methyl salicylate } \\
0.04 \% \text { 1-Menthol } \\
27 \% \text { Ethanol }\end{array}$ & $\begin{array}{c}\text { Johnson \& Johnson K.K. Consumer Company, } \\
\text { Morris Plains, NJ, USA }\end{array}$ & 4.3 \\
\hline $\begin{array}{l}\text { Popiyodon Gargle }^{\circledR} \\
\text { povidone-iodine } \\
\text { (PVP-I) (x20) }\end{array}$ & $7 \%$ povidone iodine & Yoshida Pharmaceutical Co., Ltd, Saitama, Japan & 3.6 \\
\hline
\end{tabular}

Mouthwashes were diluted according to manufactures recommendation before use.

\section{MATERIALS AND METHODS}

The effects of different mouthwashes on cariogenic bacterial survival and caries-forming potential were evaluated in models employing: 1) cultured cariogenic bacterial cells; 2) cariogenic bacteria organized into biofilms; and 3) an ex vivo caries model.

\section{EFFECTS ON CARIOGENIC BACTERIAL CELLS}

\section{Bacterial Isolates and Growth Media}

Two laboratory strains of cariogenic bacteria, Streptococcus mutans MT8148 (S. mutans) and Streptococcus sobrinus 6715 (S. sobrinus), were used in this study. Bacteria cultures were established in brain heart infusion (BHI) broth (Becton Dickinson, Sparks, MD, USA $®)$ ). After 16 hours, when bacteria were in an exponential growth phase, these cells were collected, washed 3 times with phosphatebuffered saline (PBS), and were suspended in PBS at $2.0 \times$ $10^{7}$ colony-forming units (CFU) per $\mathrm{ml}$ (correlating to an optical density at 500-nm wavelength $\left[\mathrm{OD}_{500}\right]$ of 2.0). Bacterial suspensions were stored at $4^{\circ} \mathrm{C}$ with continuous gentle stirring until use.

\section{Solution Preparation}

The solutions used in this study are listed in Table $\mathbf{1 .}$ Each commercial mouthwash was used at a dilution recommended by the respective manufacturer, and dilutions were made using Milli-Q water. PBS alone was included as a control.

\section{Inoculation of Bacteria with Solutions}

One-milliliter aliquots of the bacterial suspensions were centrifuged $\left(800 \mathrm{~g} 5 \mathrm{~min} 4^{\circ} \mathrm{C}\right)$, supernatants were discarded, and bacterial pellets were suspended in $1.0 \mathrm{ml}$ of the test solutions by gentle vortexing. Immediately after 10 -second incubation in test solutions, cell suspensions were centrifuged, the supernatants discarded, and cell pellets were suspended and held in $1.0 \mathrm{ml}$ of chilled PBS to be analyzed for viability.

\section{Bacterial Viability Test Using BacLight Kit}

A LIVE/DEAD BacLight Bacterial Viability Kit (Molecular Probes, Invitrogen Detection Technologies, Carlsbad, CA, USA $($ ) ) was used to evaluate bacterial cell killing by the test solutions. One-half $(500 \mu \mathrm{l})$ of each bacterial sample was suspended in PBS and transferred into dark microtubes, and stained with $0.5 \mu 1$ BacLight stain (a mixture of SYTO 9 and propidium iodide). In this staining system, viable bacterial cells exhibit green fluorescence, whereas nonviable bacterial cells exhibit red fluorescence. Selective dye uptake depends upon cell membrane integrity, allowing dead bacteria to be easily distinguished from viable bacteria. The excitation/emission wavelengths of the dyes were approximately 480/530 nm for SYTO 9 (green signals) and 520/580 nm for propidium iodide (red signals). Bacterial cells were evaluated using a fluorescence microscope (CKX41, Olympus, Tokyo, Japan $($ )).

\section{Colony Forming Units of Bacteria}

Each bacterial cell suspension $(500 \mu \mathrm{l})$ was serially diluted to a 1000-fold final dilution, homogenized (UP50H, Dr. Hielscher, GmbH, Baden-Wuerttemberg, Germany $\left({ }^{\circledR}\right)$ before plating with a spiral plating instrument (Eddy Jet, IUL, Barcelona, Spain $\left({ }^{\circledR}\right)$. Treated and control S..mutans and $S$. sobrinus samples were plated in petri dishes containing Mitis Salivarius (MS) agar medium (Becton Dickinson, Sparks, MD, USA $\left.{ }^{\circledR}\right)$. After a 48-hour incubation under anaerobic conditions at $37^{\circ} \mathrm{C}$, the number of CFUs was counted by light microscopy.

\section{Effects on Cariogenic Biofilms}

We evaluated the effects of different mouthwashes on bacterial viability in cariogenic biofilms using previously detailed methods [16].

\section{Enamel Slab Preparation}

Bovine lower incisors from 20- to 24-month-old cattle were used to prepare square shaped dentino-enamel slabs in this study. Approximately $5 \times 4 \times 4-\mathrm{mm}$ enamel slabs were 


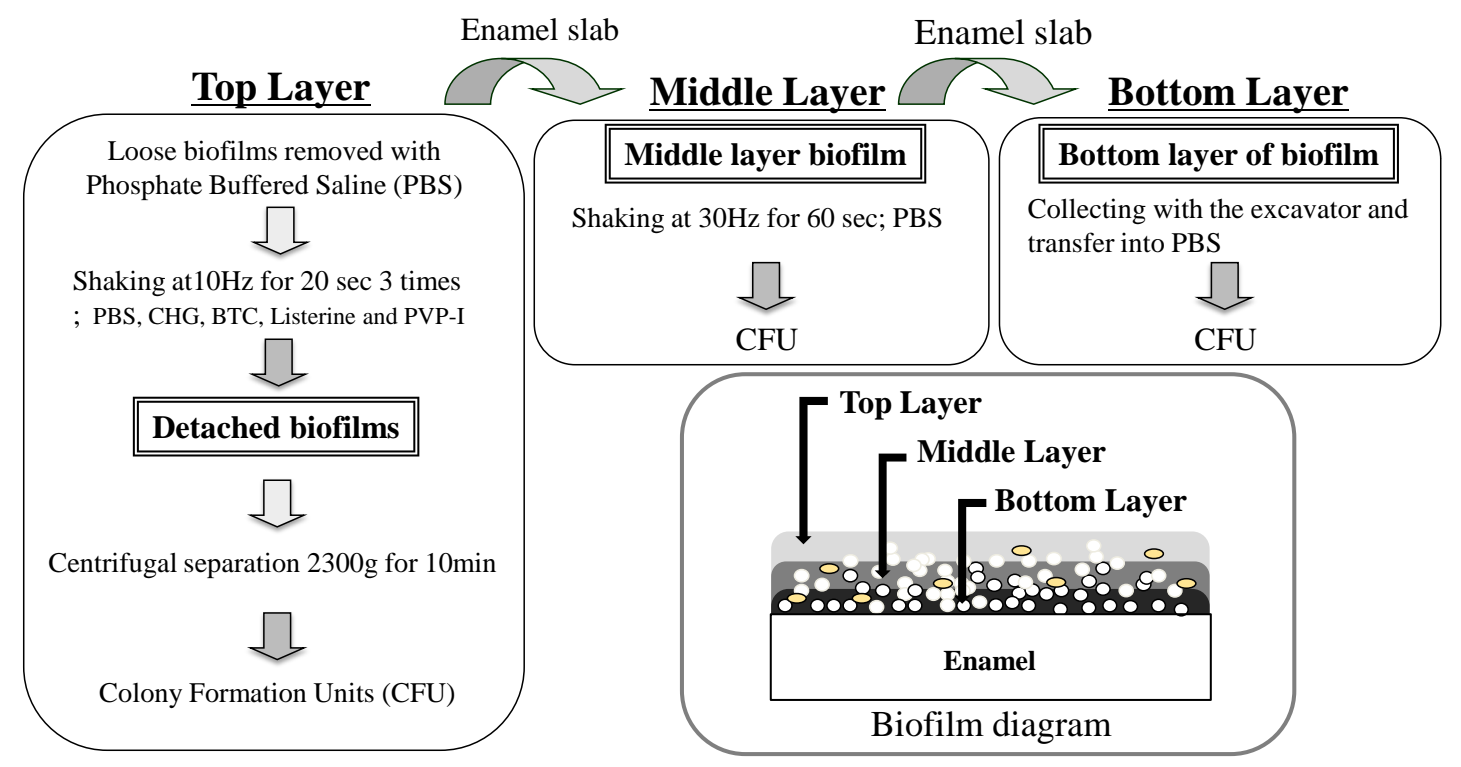

Fig. (1). Schematic diagrams show the layers of biofilms which were defined 'Top Layer', 'Middle Layer' and 'Bottom Layer' using three detachment methods.

prepared from mid-labial tooth parts by excision using a low-speed diamond disc (IsoMet, BUEHLER, IL, USA ${ }^{\circledR}$ ) under running tap water as a coolant. The convex enamel surfaces were reduced down to $0.5 \mathrm{~mm}$ thickness using 800 grit silicone carbide paper under running water, and this flat enamel surface was then polished with water-based diamond paste $(0.25-\mu \mathrm{m}$ diamond particles). Finally, the enamel slabs were ultrasonically cleaned with Milli-Q water for 15 minutes and randomly divided into five groups. Preparation of bacterial suspensions S. mutans, S. sobrinus, and Streprococcus gordonii ATCC10558 (S. gordonii) were used in this study. Bacteria were cultured in BHI broth as above, and suspensions of $S$. mutans, $S$. sobrinus and $S$. gordonii were made in PBS at $2.0 \times 10^{7} \mathrm{CFU} / \mathrm{ml}$, and stored briefly at $4^{\circ} \mathrm{C}$ with gentle stirring. For biofilm growth, a solution of Heart Infusion broth (HI; Becton Dickinson, Sparks, MD, USA $\left.{ }^{\circledR}\right)$ with sucrose (1\% final concentrations) was prepared, autoclaved and stored at $4^{\circ} \mathrm{C}$ until use.

\section{Biofilm Formation}

The S. mutans, S. sobrinus, and S. gordonii suspensions were used to form biofilms on the enamel slab surfaces that had been placed inside the water jacket-encircled chamber of an oral biofilm reactor (OBR) $[17,18]$. Twenty enamel slabs were positioned on specimen holders in OBR chambers around a flat-bulb $\mathrm{pH}$ electrode using red utility wax (GC, Tokyo, Japan). Thereafter, the polished enamel surface of each enamel slab was subjected to biofilm attachment. Pooled sterile saliva was poured on the specimen surfaces and incubated for 30 minutes to obtain a coating of salivary pellicle. Artificial biofilms were then grown on enamel sections inside the OBR chambers for 12 hours.

Enamel slabs were then gently shaken at $5 \mathrm{~Hz}$ for $3 \mathrm{~min}$ utes in chilled PBS to remove loose biofilms. Remaining bacterial biofilms on enamel sections were then inoculated with $1.0 \mathrm{ml}$ of the each of the mouthwash test solutions in microtubes $(n=3$ replicates for each test solution in each experiment). Microtubes containing the enamel slabs in test solutions were shaken three times using a Tissue Lyser at 10 $\mathrm{Hz}$ for 20 seconds each time (Fig. 1). At this stage the detached biofilms were defined as the biofilm "Top Layer". Each enamel slab was then transferred to a fresh tube containing chilled PBS and shaken using the Tissue Lyser for an additional 60 seconds at $30 \mathrm{~Hz}$. The biofilms detached after the second shaking were defined as the biofilm "Middle Layer". Each enamel slab was again transferred in chilled PBS to a fresh microtube. The retained biofilms were manually removed with a scraper and were collected in fresh microtubes with chilled PBS. These were defined as biofilm "Bottom Layers". Collected biofilms were diluted 1000-fold with PBS, homogenized, and then were plated on MS agar medium. After incubation for 48 hours under anaerobic conditions at $37^{\circ} \mathrm{C}$, CFUs were counted using a light microscope. This experiment was repeated three times, using triplicate plates per condition.

\section{Mouthwash Potential to Inhibit Caries Formation}

An artificial caries model was used for this experimental series to evaluate whether different mouthwashes can effectively inhibit caries formation (Fig. 2) [19, 20].

\section{Enamel Slab Preparation, Cavity Formation, and Composite Restoration}

Enamel slabs were prepared from bovine incisors as detailed above. After rinsing with ultrapure water, enamel section were dried and coated with fingernail varnish (Fig. 2). Class-1 cavities ( $3 \mathrm{~mm}$ long, $2 \mathrm{~mm}$ wide, $2 \mathrm{~mm}$ deep) were prepared on the surface of the enamel slabs using a 0.8-1.0 $\mathrm{mm}$ diameter regular-grit tapered burr (ISO \#170, Shofu, Kyoto, Japan (®) mounted in a milling machine (Cendres \& Metaux SA CH-2501, Biel-Bienne, Switzerland $\left.{ }^{\circledR}\right)$, and cavity surfaces were finished with a straight burr (ISO \#109, Shofu $(\mathbb{B})$ under water coolant. A light curing self-etching one component adhesive material (iBOND; Heraeus Kulzer, Hanau, Germany ${ }^{\circledR}$ ) and a hybrid composite (Clearfil AP-X; Kuraray Medical, Tokyo, Japan $(\circledR)$ were used to fill the cavi- 
Table 2. Materials Used in this Study

\begin{tabular}{|c|c|c|c|c|}
\hline Material & Lot Number & Composition & Procedure & Manufacturer \\
\hline \hline iBOND & 010092 & $\begin{array}{c}\text { Acetone, UDMA, TEGDMA, } \\
\text { 4-methacryloxyethyltrimellitic } \\
\text { anhydride, glutaraldehyde, } \\
\text { Photoinitiator }\end{array}$ & $\begin{array}{c}\text { Apply and wait for 30 s, } \\
\text { Gentle and thorough air- } \\
\text { drying and light-cure 20 s s }\end{array}$ & $\begin{array}{c}\text { Heraeus Kulzer Inc., } \\
\text { Hanau, Germany }\end{array}$ \\
\hline Clearfil AP-X & 00972A & $\begin{array}{c}\text { Bis-GMA, TEGDMA, Photoinitiator, Barium glass, Silanated } \\
\text { colloidal silica (filler content 85.0 wt\%) }\end{array}$ & Light-cure 40 s & $\begin{array}{c}\text { Kuraray Medical Inc., } \\
\text { Tokyo, Japan }\end{array}$ \\
\hline
\end{tabular}

UDMA, urethane dimethacrylate; TEGDMA, triethylene glycol dimethacrylate; Bis-GMA, bisphenol-A diglycidyl methacrylate;

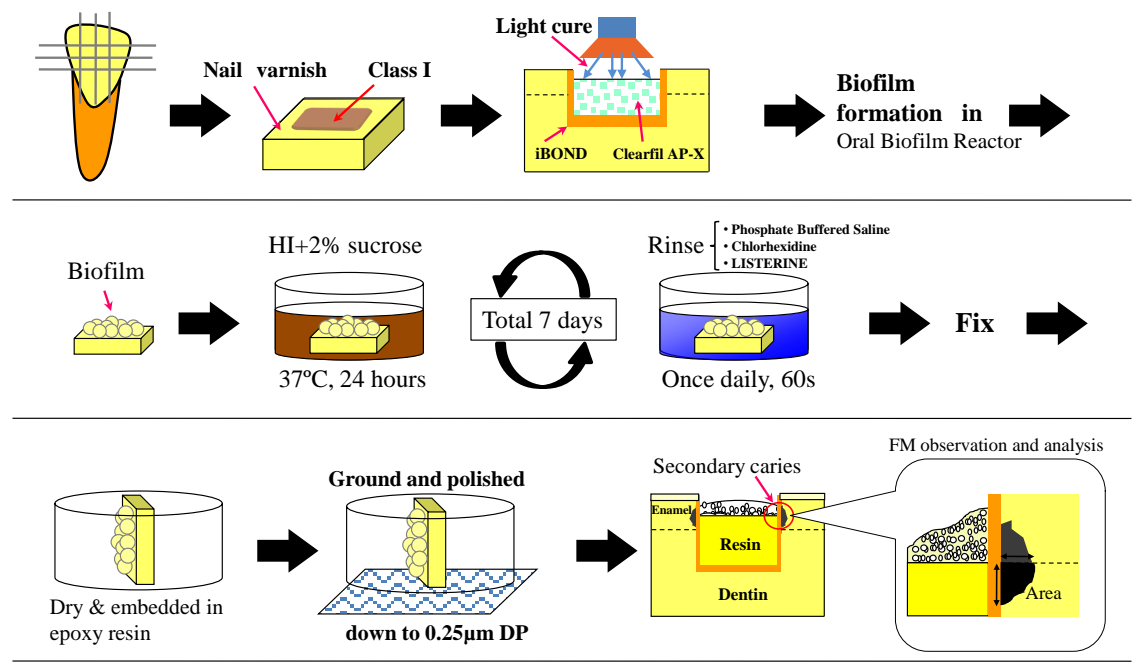

Fig. (2). Schematic diagrams sequentially show the specimen preparation, secondary carie induction, and observation using a fluorescence microscope (FM). Class-1 type cavities were prepared, immediately restored with resin composite, followed by $S$. mutans biofilm formation using an oral biofilm reactor (OBR). Specimens were then rinsed once daily with the antiseptic mouthwash solutions during the final 7-day incubation period. Location of the measured lesion area is indicated.

ties. The lot numbers and chemical compositions of the materials with manufacturer instructions are listed in Table 2. The cavities were not filled completely, and 0.8 -mm-deep unfilled spaces remained as the site for biofilm accumulation (Fig. 2).

As detailed above, suspensions of exponentially growing S.mutans, S. sobrinus, and S. gordonii were washed three times in PBS, and suspended in chilled PBS with gentle stirring until use.

\section{Growing Biofilms on Enamel Slabs Inside the OBR}

Inside the OBR, artificial $S$. mutans, $S$. sobrinus, and $S$. gordonii biofilms were grown on each of the Class- 1 cavities that were filled with resin composite material. After 24 hours in the OBR chamber, specimen with de novo biofilms were transferred to 24-well tissue culture plates (Corning Inc., New York, NY, USA $®)$ and were incubated at $37^{\circ} \mathrm{C}$ in $\mathrm{HI}$ medium containing $1 \%$ sucrose for a further 7 days, with media replenished every other day.

\section{Evaluating Mouthwash Effects on Caries Development}

During the 7-day incubation period in HI, specimens were rinsed with either Listerine, chlorhexidine gluconate (CHG), or PBS ( $\mathrm{n}=4$ replicated in each group) for $60 \mathrm{sec}-$ onds once daily. Samples were mildly agitated in the test solutions using a water bath shaker operating at $10 \mathrm{~Hz}$, for 20 seconds, three times, at 1-minute intervals.

\section{Fluorescence Microscopic Evaluation of Caries}

To detect and morphometrically measure the demineralized lesions in the caries model, at the end of the experiment, enamel samples were rinsed with PBS, and fixed in $4 \%$ paraformaldehyde and 1\% glutaraldehyde in PBS for 1 hour. Samples were rinsed with PBS three times, followed by final rinsing in Milli-Q water, air-drying, and were then embedded in a self-curing epoxy resin (Epon 815, Nissin EM, Tokyo, Japan () ). Enamel specimens were subsequently ground with 800-grit silicon carbide paper and diamond paste to expose the longitudinal axis and provide a clear view of the cavity site. Secondary caries lesions at the enamel/composite interfaces were evaluated on an inverted fluorescence microscope, and imaged using a DP70 system with the aid of DP Manager Software (Olympus). Images were taken at $\times 40$ and $\times 100$ magnifications after setting a scale bar for each micrograph. Lesion areas were subsequently measured using Image_J V.1.34 software 20 (NIH, Bethesda, MD) utilizing the scale bar on each image as a calibration reference. Only the regions of a lesion that remained adjoined with resin were classified as secondary caries lesions (Fig. 2).

\section{Statistical Analysis}

All numerical data was analyzed using the Statistical Package for the Medical Sciences (SPSS Ver.11 for Windows, SPSS Inc., Chicago, IL, USA). The experiments were repeated three times under the same conditions to ensure reproducibility. For data from experiments comparing 


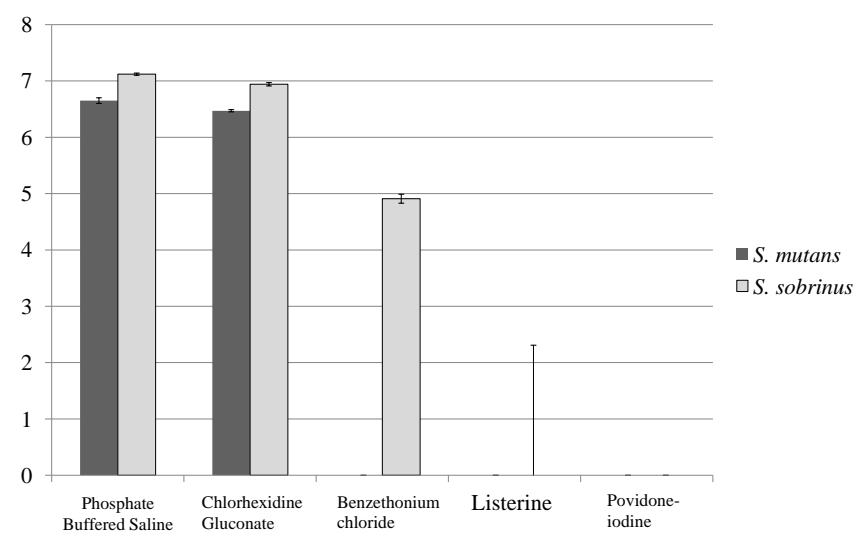

Fig. (3). Graphic representation of bacterial colony numbers on Mitis Salivarius (MS) agar plates after bacteria treatment with the solutions. Data are expressed as the mean $\log _{10}$ of colony-forming units per $\mathrm{ml}(\mathrm{CFU} / \mathrm{ml})$. All numerical data were evaluated for statistically significant differences by analyses using the non-parametric Kruskal-Wallis test followed Mann-Whitney's U test. $(\mathrm{P}<0.05), \mathrm{n}=12$.

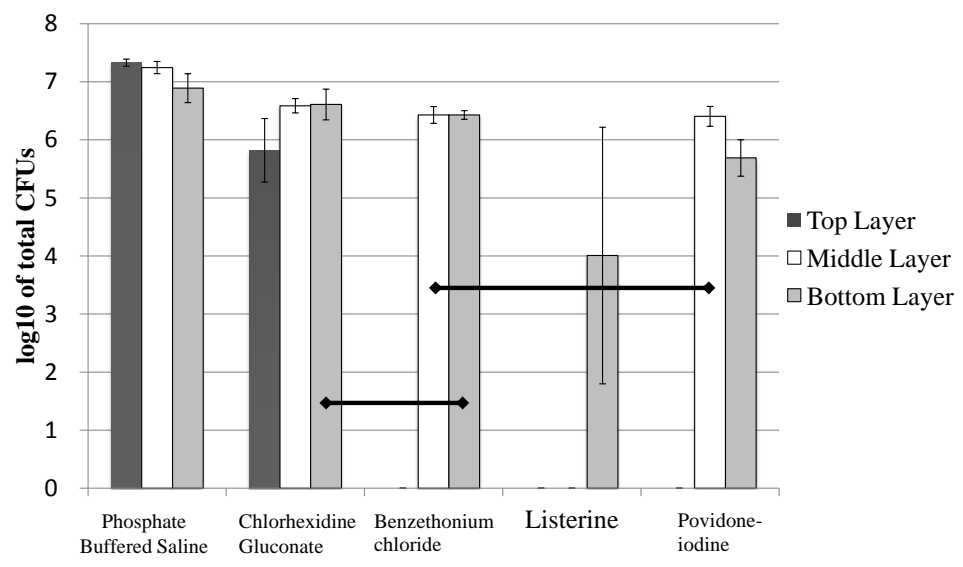

Fig. (4). Graphic representation of bacterial colony numbers on Mitis Salivarius (MS) agar plates after treatment of biofilms with the solutions. Data are expressed as the mean $\log 10$ of colony-forming units per $\mathrm{ml}(\mathrm{CFU} / \mathrm{ml})$. Horizontal lines indicate statistically no significant differences after analyses using the non-parametric Kruskal-Wallis test followed by Mann-Whitne's U test $(\mathrm{P}>0.05), \mathrm{n}=9$.

mouthwash effectiveness against bacterial cell suspensions and biofilms, we used the non-parametric Kruskal-Wallis test initially for multiple comparisons, followed by the Mann-Whitney U-test to compare two sample sets (samples that showed no bacterial growth were excluded).

For data from the caries models, the maximum width and length, and area of secondary caries lesions were analyzed by one-way analysis of variance (ANOVA) and Tukey's honestly significant difference (HSD) test with a confidence level of $95 \%$.

\section{RESULTS}

\section{Bacterial Viability after Short Exposure to Different Mouthwashes}

By fluorescence microscopy using the Live/Dead cell viability assay, live bacterial cells appear green and dead cells are red in the same microscopic image, following excitation with blue light (supplementary data). Clearly, more live bacterial cells are visible than dead cells in all experimental groups except for the cells treated with Listerine. Nearly $100 \%$ cells in our PBS controls were alive, and only slight killing was observed in bacteria treated with CHG. About $50 \%$ of bacteria died after treatment with povidone-iodine (PVP-I) or benzethonium chloride (BTC). Essentially all bacterial cells were killed after a short treatment with Listerine.

\section{Colony Forming Units of Cariogenic Bacteria after Mouthwash Exposure}

Colony counts $(\mathrm{CFU} / \mathrm{ml})$ of bacterial cells recovered from each sample are shown in Fig (3). Expectedly, the number of viable bacterial cells after incubation with the test solutions varied depending on the chemical components and their concentrations. Significantly more bacterial colonies were counted with cells that were treated with PBS and CHG compared to other solutions $(\mathrm{P}<0.05)$. Almost no colonies were observed when cells were treated with either Listerine or PVP-I. Both S. mutans and S. sobrinus bacteria cultures responded similarly to mouthwash exposure; in the case of BTC, however, S. sobrinus appeared to be more resistant to BTC antiseptic action.

\section{Disinfection Effects after Penetration Inside Cariogenic Biofilms}

The viability of bacterial cells recovered from each biofilm group is summarized in Fig. (4). Among "Top Layer" samples, there was no detectable colony growth following exposure to Listerine, PVP-I, or BTC, CHG showed more than $4 \times 10^{6} \mathrm{CFU} / \mathrm{ml}$. BTC and PVP-I showed reduced 


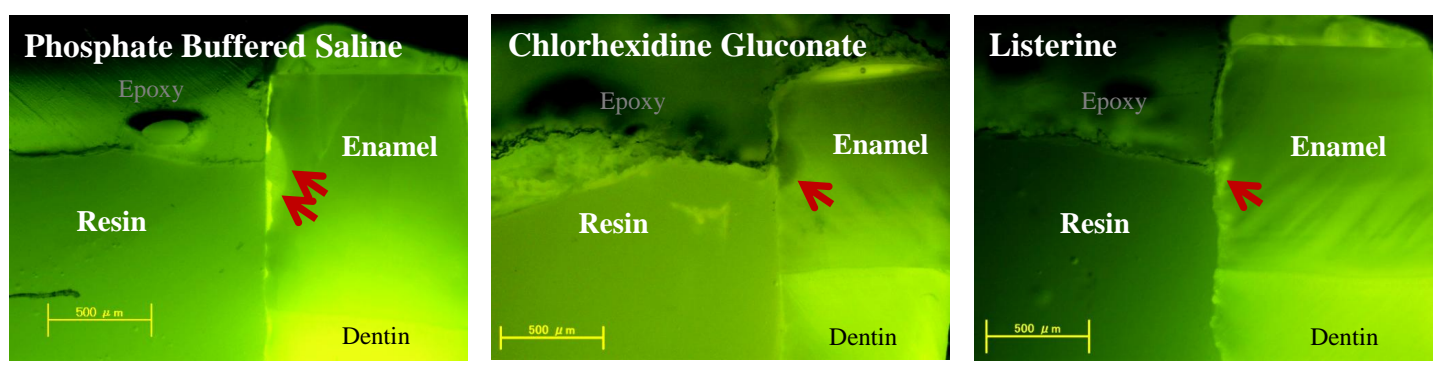

Fig. (5a). Photomicrographs represent a typical sized lesion from each experimental group taken by fluorescence microscopy. Demineralized regions are indicated by red arrows. Lesion size was largest in the phosphate-buffered saline control group and was smallest in Listerine group. The chlorhexidine gluconate group displayed larger lesions than the Listerine group. ('Epoxy' indicates the polymer resin used for embedding the samples).

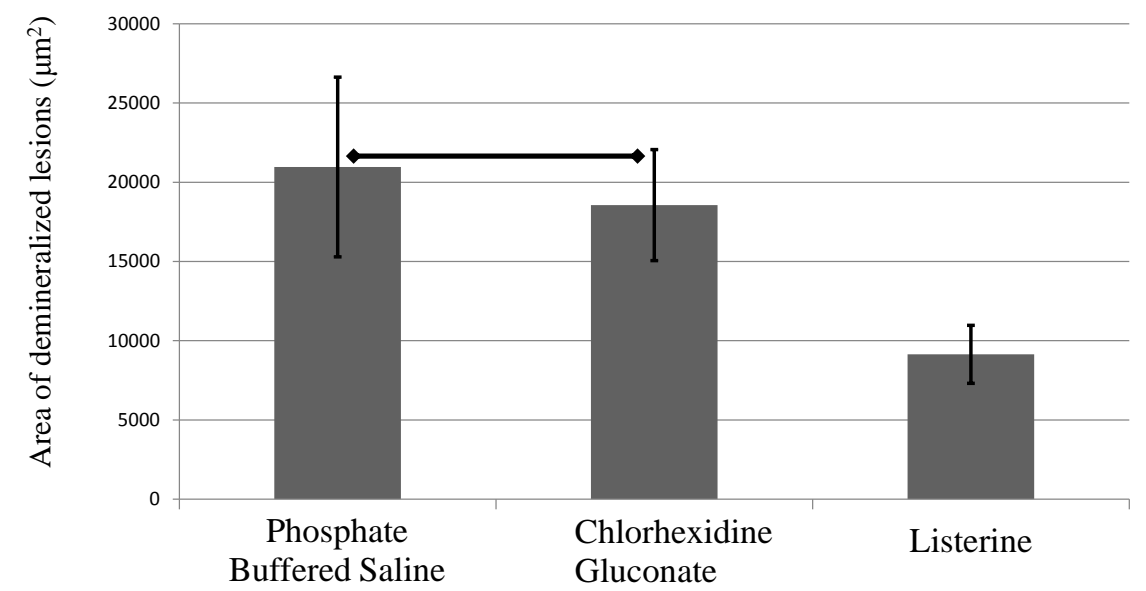

Fig. (5b). Graph represents the average size of the lesion in each group. Horizontal lines indicate statistically no significant differences as analyzed by one-way analysis of variance and Tukey's honestly significant difference test $(\mathrm{P}>0.05, \mathrm{n}=7)$.

colony numbers compared to CHG. PBS controls, as expected, showed robust colony growth. Among "Middle Layer" biofilm samples, BTC and PVP-I resulted in significantly less colony growth compared to PBS controls. Listerine treatment resulted in no detectable colonies. Among "Bottom Layer" biofilm samples, CHG treatment resulted in more colonies than did BTC or PVP-I. Listerine treated biofilms generated only very few colonies and their numbers were significantly less than in all of the other groups.

\section{Inhibition Potential of Mouthwashes Against Caries Progression}

On fluorescence microscopic inspection, carious lesions were detected in enamel at the edge of resin restorations (Fig. 5a). These appeared as demineralized enamel that exhibited a whitish-green fluorescence (PBS group), In some cases, dislodgement of brittle enamel prisms after demineralization was also observed as dark voids ( $\mathrm{CHG}$ group). The Listerine group had the smallest lesions among the three groups (Fig. 5a), which were significantly different $(\mathrm{P}<0.05)$ compared to the other two groups (Fig. 5b). The CHG group had smaller lesions compared to PBS group, but this difference did not reach statistical significance (Fig. 5b).

\section{DISCUSSION}

Mouthwashes experimented with in this study displayed heterogeneous potency in terms of bactericidal effects and inhibiting carious lesion formation. All four mouthwashes contain completely different chemical compositions. These compounds are mostly synthetically produced and have been used for many clinical purposes including, for example, dental plaque control, oral pathogen elimination, and to prevent and treat halitosis [21].

BTC, Listerine, and PVP-I were all effective in killing cariogenic bacteria after brief exposure in suspension. Listerine in particular showed the strongest disinfection effect on planktonic bacteria and on the bacteria that were protected inside biofilms by water insoluble glucans compared to other mouthwashes. This might be because Listerine contains multiple antibacterial reagents including essential oils and ethanol in high concentration, and is recommended to be used without dilution.

Mouthwashes including chlorhexidine digluconate and Listerine are being critically investigated for their disinfection effects against oral pathogens [22]. BTC, containing $0.01 \%(\mathrm{w} / \mathrm{v})$ benzethonium chloride, is a commonly used antiseptic in Japan. The BTC product evaluated in the current work combines benzethonium chloride with tea tree and white thyme oils, both of which have been studied as antiinfective agents [23, 24]. PVP-I not only destroys bacteria, but also effectively inhibits the release of pathogenic factors [25]. Listerine also has previously been demonstrated to exert significant microbicidal activity against oral microorganisms [26].

On the other hand, it has been reported that a $0.12 \%$ chlorhexidine mouth rinse was superior to Listerine in maintaining low plaque and gingivitis scores, in the absence of 
mechanical plaque control [27]. However, in that study gargling with CHG for 10 seconds did not result in bactericidal activity when using $0.0005 \%$ CHG (i.e., a 100-fold dilution of standard $0.05 \%$ oral rinses). We actually did not expect that $\mathrm{CHG}$ would demonstrate bactericidal effects at such a low concentration when employed in the present experimental series. In Japan, the use of chlorhexidine is limited because it has caused allergic reactions and anaphylactic shock in some patients [28]. Because of this, only very low concentrations of $\mathrm{CHG}$ are permitted for homecare use, and all types of chlorhexidine-containing anti-bacterial agents are used with maximum caution [29]. CHG also contains monoammonium glycyrrhizinate, which is often used as a sweetening and flavoring agent, and also found to be effective in controlling lung inflammation in mice [30]. Perhaps, low CHG concentrations permit more frequent use for long-term prophylactic therapy with the additional benefit of controlling inflammation.

Of the different bactericidal mouthwashes that we evaluated for killing bacteria in suspension and in biofilms, we demonstrated that Listerine is the most potent and CHG is the weakest oral antiseptic. Therefore, we selected these two mouthwashes for further evaluation in caries inhibition assays. Data from these studies clearly showed that Listerine effectively inhibited the progression of caries and secondary caries development in our cavity model. Expectedly, CHG at the concentration of $0.0005 \%$ did not show a detectable bacterial inhibitory activity in this study.

The specimens with the undisturbed biofilms were inoculated for an additional 7 days to observe the ability of the two mouthwashes to inhibit the progression of carious lesions or enamel demineralization. In this study, a water bath shaker was used with a moderate stroke of $10 \mathrm{~Hz}$ for $20 \mathrm{sec}-$ onds three times at 1-minute intervals to simulate the gargling condition created by an adult.

Mouthwashes containing strong chemical reagents, such as Listerine, are not advisable for long-term continuous use. They not only dry up the mucous membranes and potentially damage soft tissues, but also may cause a severe imbalance in the oral microbial flora. Excessive use of low-pH mouthwashes over long periods of time is also of concern. The $\mathrm{pH}$ at which tooth demineralization begins is known as the critical $\mathrm{pH}$, and is in the vicinity of $\mathrm{pH} 5.0$ to 5.5 . Demineralization is most rapid following acute exposure to $\mathrm{pH} 4.0$, as is often observed in mature dental plaques after a sugar exposure $[8,31]$. It was also reported that low $\mathrm{pH}$ mouthwashes and soft drinks have a variable potential to cause enamel erosion $[32,33]$. Therefore, it is important to control the $\mathrm{pH}$ in the oral environment [34]. However, the critical pH level below which damage to the enamel or tooth demineralization is observed, is known to be 5.5 [6]. One unfortunate fact is that the $\mathrm{pH}-\mathrm{levels}$ of currently available Listerine and PVP-I are both lower than the critical $\mathrm{pH}$ (Table 1). Periodic use, according to immediate need and under appropriate guidance of a specialized dental professional is important to obtain maximum benefit while avoiding potential chemical toxicity and subsequent oral tissue damage. One of the reasons for selecting a short exposure time (10 second vortex) of our bacterial suspensions and biofilms to the mouthwashes in this study was to provide evidence that short exposure to these antibacterial agents can be remarkably effective [34]. Short exposure times also minimize chemical biohazard concerns associated with oral antiseptic use.

\section{CONCLUSION}

Bactericidal potency varies significantly according to the specific chemical components and their concentrations of different mouthwashes. We suggest that mouthwashes such as Listerine can be useful for prevention of caries and secondary caries if used within appropriate guidelines. Further long-term studies including additional antibacterial mouthwashes or prophylactic mouthrinses, are recommended.

\section{ACKNOWLEDGEMENTS}

This work was supported by the Global Center of Excellence Program; International Research Center for Molecular Science in Tooth and Bone Diseases at Tokyo Medical and Dental University, Tokyo, Japan.

\section{CONFLICT OF INTEREST}

None declared.

\section{SUPPLEMENTARY MATERIAL}

Supplementary material is available on the publisher's web site along with the published article.

\section{REFERENCES}

[1] Pitten FA, Kramer A. Antimicrobial efficacy of antiseptic mouth rinse solutions. Eur J Clin Pharmacol 1999; 55: 95-100.

[2] Selwitz RH, Ismail AI, Pitts NB. Dental caries. Lancet 2007; 369: 51-9.

[3] Featherstone JD. The science and practice of caries prevention. J Am Dent Assoc 2000; 131: 887-99.

[4] Kanasi E, Johansson I, Lu SC, et al. Microbial risk markers for childhood caries in pediatrician's offices. J Dent Res 2010; 89: 37883.

[5] Hamada S, Slade HD. Biology, immunology, and cariogenicity of streptococcus mutans. Microbiol Rev 1980; 44: 331-84.

[6] Loesche WJ. Role of Streptococcus mutans in human dental decay Microbiol Rev 1986; 50: 353-80.

[7] Marsh PD. The role of microbiology in models of dental caries. Adv Dent Res 1995; 9: 244-54.

[8] Kleinberg I. A mixed-bacteria ecological approach to understanding the oral bacteria in dental caries causation an alternative to Streptococcus mutans and the specific-plaque hypothesis. Crit Rev Oral Biol Med 2002; 13: 108-25.

[9] Filoche SK, Soma D, van Bekkum M, Sissons CH. Plaques from different individuals yield different microbiota responses to oralantiseptic treatment. FEMS Immunol Med Microbiol 2008; 54: 27 36.

[10] Fischman SL. The history of oral hygiene products: how far have we come in 6000 years? Periodontology 2000 1997; 15: 7-14.

[11] Russell AD. Bacterial adaptation and resistance to antiseptics, disinfectants and preservatives is not a new phenomenon. J Hosp Infect 2004; 57: 97-104.

[12] Yoneyama A, Shimizu M, Tabata M, Yashiro J, Takata T, Hikida M. In vitro short-time killing activity of povidone-iodine (Isodine Gargle) in the presence of oral organic matter. Dermatology 2006; 212: 103-8.

[13] Erciyas AF, Erciyas K, Sarıkaya R. Genotoxicity of two mouthwash products in the drosophila wing-spot test. Food Chem Toxicol 2010; 48: 2577-80.

[14] Gosau M, Hahnel S, Schwarz F, Gerlach T, Reichert TE, Bürgers R. Effect of six different peri-implantitis disinfection methods on in vivo human oral biofilm. Clin Oral Implants Res 2010; 21: 866-72.

[15] Filoche SK, Soma D, van Bekkum M, Sissons CH. Plaques from different individuals yield different microbiota responses to oralantiseptic treatment. FEMS Immunol Med Microbiol 2008; 54: 2736 . 
[16] Okada A, Matin K, Hanada N, Tagami J. Electrolyzed Waters with different hypochlorite concentrations in controlling cariogenic biofilms. The IADR 86th General Session \& Exhibition, Toronto, 2008; pp. 2-5.

Available from: http://iadr.confex.com/iadr/2008Toronto/techprogram/abstract_106132.htm.

[17] Ono M, Nikaido T, Ikeda M, et al. Surface properties of resin composite materials relative to biofilm formation. Dent Mater J 2007; 26: 613-22.

[18] Gyo M, Nikaido T, Okada K, Yamauchi J, Tagami J, Matin K. Surface response of fluorine polymer-incorporated resin composites to cariogenic biofilm adherence. Appl Environ Microbiol 2008; 74: 1428-35.

[19] Hayati F, Okada A, Kitasako Y, Tagami J, Matin K. An artificial biofilm-induced secondary caries model for in vitro studies. Aust Dent J 2011; 56: 40-7.

[20] Uchida R, Matin K, Tagami J. An in vitro study to assess the efficacy of $\mathrm{OH}^{-}$ion superadded alkali-ion water in inhibiting caries and secondary caries. Asian Pac J Dent 2011; 11: 1-8.

[21] Ozan F, Sümer Z, Polat ZA, Er K, Ozan U, Deger O. Effect of mouthrinse containing propolis on oral microorganisms and human gingival fibroblasts. Eur J Dent 2007; 1: 195-201.

[22] Baffone W, Sorgente G, Campana R, Patrone V, Sisti D, Falcioni T. Comparative effect of chlorhexidine and some mouthrinses on bacterial biofilm formation on titanium surface. Curr Microbiol 2011; 62: 445-51.

[23] Caelli M, Porteous J, Carson CF, Heller R, Riley TV. Tea tree oil as an alternative topical decolonization agent for methicillinresistant Staphylococcus aureus. J Hosp Infect 2000; 46: 236-7.

[24] Inouye S, Yamaguchi H, Takizawa T. Screening of the antibacterial effects of a variety of essential oils on respiratory tract pathogens, using a modified dilution assay method. J Infect Chemother 2001; 7: $251-4$.
[25] Darouiche RO, Wall MJ Jr, Itani KM, et al. Chlorhexidine-alcohol versus povidone-iodine for surgical-site antisepsis. N Engl J Med 2010; 362:18-26.

[26] Pan P, Barnett ML, Coelho J, Brogdon C, Finnegan MB. Determination of the in situ bactericidal activity of an essential oil mouthrinse using a vital stain method. J Clin Periodontol 2000; 27: 256-61.

[27] Sekino S, Ramberg P. The effect of a mouth rinse containing phenolic compounds on plaque formation and developing gingivitis. $\mathbf{J}$ Clin Periodontol 2005; 32: 1083-8.

[28] Okano M, Nomura M, Hata S, et al.. Anaphylactic symptoms due to chlorhexidine gluconate. Arch Dermatol 1989; 125: 50-2.

[29] Nakagawa T, Hosaka Y, Ishihara K, et al. The efficacy of povidone-iodine products against periodontopathic bacteria. Dermatology 2006; 212: 109-11.

[30] Shi JR, Mao LG, Jiang RA, Qian Y, Tang HF, Chen JQ. Monoammonium glycyrrhizinate inhibited the inflammation of LPS-induced acute lung injury in mice. Int Immunopharmacol 2010; 10: 123541.

[31] Pontefract H, Hughes J, Kemp K, Yates R, Newcombe RG, Addy $\mathrm{M}$. The erosive effects of some mouthrinses on enamel. a study in situ. J Clin Periodontol 2001; 28: 319-24.

[32] Järvinen VK, Rytömaa II, Heinonen OP. Risk factors in dental erosion. J Dent Res 1991; 70: 942-7.

[33] ten Gate JM, Imfeld T. Dental erosion, summary. Eur J Oral Sci 1996; 104: 241-4.

[34] Oyanagi T, Matin K, Uchida R, Tagami J. Inhibition potential of hypochlorous-acid electrolyzed water against progression of caries. IADR/AADR/CADR 89th General Session and Exhibition, San Diego, California 2011 March 16-19. Available from: http://iadr.confex.com/iadr/2011sandiego/webprogram/Paper14594 6.html

(C) Oyanagi et al.; Licensee Bentham Open.

This is an open access article licensed under the terms of the Creative Commons Attribution Non-Commercial License (http://creativecommons.org/licenses/by-nc/3.0/) which permits unrestricted, non-commercial use, distribution and reproduction in any medium, provided the work is properly cited. 